\section{CREEP BEHAVIOR IN SiC WHISKER-REINFORCED ALUMINA COMPOSITE}

\section{RECEIVED}

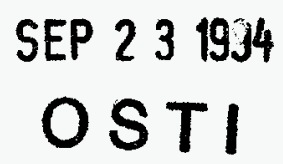

Hua-Tay Lin and Paul F. Becher

Metals and Ceramics Division

Oak Ridge National Laboratory

Oak Ridge, TN 37831-6068

\begin{abstract}
Grain boundary sliding (often accompanied by cavitation) is a major contributor to compressive and tensile creep deformation in fine-grained aluminas, both with and without whisker-reinforcement. Studies indicate that the creep response of alumina composites reinforced with $\mathrm{SiC}$ whiskers can be tailored by controlling the composite microstructure and composition. The addition of SiC whiskers $(<30$ vol\% $)$ significantly increases the creep resistance of fine-grained $(1-2 \mu \mathrm{m})$ alumina in air at temperatures of 1200 and $1300^{\circ} \mathrm{C}$. However, at higher whisker contents ( 30 and $\left.50 \mathrm{vol} \%\right)$, the creep resistance is degraded due to enhanced surface oxidation reactions accompanied by extensive creep cavitation. Densification aids (i.e., $\mathrm{Y}_{2} \mathrm{O}_{3}$ ), which facilitate silica glass formation and thus liquid phase densification of the composites, can also result in degradation of creep resistance. On the other hand, increasing the matrix grain size or decreasing the whisker aspect ratio (increasing whisker number density) results in raising the creep resistance of the composites. These observations not only explain the variability in the creep response of various $\mathrm{SiC}$ whisker-reinforced alumina composites but also indicate factors that can be used to enhance the elevated temperature performance.
\end{abstract}

\title{
INTRODUCTION
}

Reinforcement by discontinuous whiskers or continuous fibers resulted in substantial improvements in fracture toughness and damage tolerance of ceramic-based composites over conventional monolithic ceramics. For instance, the addition of SiC whiskers led to substantial enhancements in fracture, slow crack growth, thermal shock, and static/cyclic fatigue resistances of monolithic aluminas. ${ }^{1-5}$ The increased toughness in these ceramic composites is derived from the operative toughening mechanisms of fiber/whisker bridging and pullout behind the crack tip. ${ }^{6}$ In addition, research also showed that the alumina composites retained their strength and fracture toughness to temperatures of $1000-1100^{\circ} \mathrm{C}$ in an oxidizing environment. ${ }^{3}$ This was also coupled with the much superior resistance to elevated-temperature delayed failure and creep deformation in alumina composites as compared with polycrystalline fine-grained aluminas.3,7 These excellent mechanical properties indicate that the alumina-SiC composites exhibit potential for high-temperature structural applications.

However, studies showed that the strength, fracture toughness, and time to failure of alumina-SiC-whisker composites and other advanced toughened ceramics were limited 


\section{DISCLAIMER}

Portions of this document may be illegible in electronic image products. Images are produced from the best available original document. 
by the slow crack growth and/or creep processes when subjected to various applied stress states at elevated temperatures. ${ }^{8-11}$ The rupture lifetime was dictated by the nucleation and growth of cavities at grain boundary and subsequent cavity coalescence to form micro cracks followed by formation of a critical crack and catastrophic failure. Furthermore, the $\mathrm{SiC}$ whiskers incorporated in the alumina composites were oxidized at elevated temperatures in air. The glassy phases formed by the oxidation of $\mathrm{SiC}$ whiskers along the crack paths exposed to air can facilitate the creep deformation processes and shorten the creep life. The creep plus oxidation reaction processes therefore played a key role in determining the long-term mechanical reliability and chemical stability of alumina-SiC composites at elevated temperatures.

Numerous creep studies ${ }^{12-15}$ have been undertaken to investigate the influence of temperature, whisker content, environment, and whisker aspect ratio on the creep response of alumina-SiC-whisker composites. Due to differences in whisker and $\mathrm{Al}_{2} \mathrm{O}_{3}$ sources, compositions (including densification additives), as well as microstructures, it was difficult to compare results. Systematic creep studies in flexure were hence undertaken to investigate (1) the influence of $\mathrm{SiC}$ whisker reinforcement on the creep resistance of polycrystalline alumina and (2) the effects of the microstructural and compositional parameters (i.e., whisker content and densification additives) on the creep response and controlling mechanisms. ${ }^{16-19}$ The influence of matrix grain size and whisker aspect ratio on creep resistance of alumina composites were also evaluated. These results and observations will be reviewed in this paper.

\section{EXPERIMENTAL PROCEDURES}

The alumina-SiC whiskers composites used to study the effects of whisker content (20 - $50 \mathrm{vol} \%)$ and sintering additive studies were fabricated by hot-pressing alumina powder (CR-10 grade, Baikoski Corp., Charlotte, NC)-SiC whisker (Advanced Composite Materials Corp., Greer, SC) mixture at temperatures of 1800 or $1850^{\circ} \mathrm{C}$, with an applied pressure of $42 \mathrm{MPa}$ for $1 \mathrm{~h}$ in an argon environment. The $\mathrm{SiC}$ whiskers are mixtures of $\alpha$ - and $\beta$-phase polytypes with typical average diameters and lengths of 0.6 $0.8 \mu \mathrm{m}$ and $25-30 \mu \mathrm{m}$, respectively. The alumina composites reinforced with 20 vol\% SiC whiskers were also fabricated with additions of $0.4 \mathrm{wt} \% \mathrm{MgO}$ plus $0.4 \mathrm{wt} \% \mathrm{Y}_{2} \mathrm{O}_{3}$ densification additives under the same hot-pressing conditions. The densities of the hotpressed billets were $\geq 99 \%$ of the theoretical density. The average matrix grain size in these composites is $\sim 1-2 \mu \mathrm{m}$ and is insensitive to whisker content as well as addition of sintering additives.

The composites used for the studies of matrix grain size were obtained by hotpressing pre-mixed alumina-10 vol\% SiC powders that were obtained from a commercial source (Advanced Composite Materials Corp., Greer, SC) and processed by a proprietary procedure. The alumina composites with densities $\geq 99 \%$ of theoretical density were fabricated under various hot-pressing temperatures and times in order to achieve various matrix grain sizes $(1.2$ to $8.0 \mu \mathrm{m})$. The same powder mixture was also dry-milled for 100 $\mathrm{h}$ using an alumina ball media to reduce the aspect ratio of whiskers, and was subsequently hot-pressed at $1850^{\circ} \mathrm{C}$ and at $42 \mathrm{MPa}$ for $1 \mathrm{~h}$ in an argon atmosphere to $\geq 99 \%$ of theoretical density. Densification additives were not used in the studies of grain size and whisker aspect ratio effects.

Flexural creep bend bars $(2.8 \times 3.6 \times>42 \mathrm{~mm}$ or $2.5 \times 2.9 \times>25 \mathrm{~mm})$ were prepared from hot-pressed billets using diamond cutting and abrasive grinding wheels. The flexural bars were machined so that the tensile surface was perpendicular to the hotpressing direction. The tensile surfaces of the specimens were prepared by surface grinding in a direction parallel to the length of the bars with a 220 grit diamond resinoid bonded wheel followed by a final polishing to obtain a $0.3-\mu \mathrm{m}$ mirror surface finish. The tensile surface edges were beveled with a $6-\mu \mathrm{m}$ diamond polishing lap.

Flexural creep tests were conducted at $1200^{\circ}$ and $1300^{\circ} \mathrm{C}$ at selected applied stress levels in air. The alumina composite specimens were loaded in a four-point bending fixture of sintered $\alpha$-SiC (Carborundum Co., Niagara Falls, NY) with inner and outer spans of 6.4 and $19 \mathrm{~mm}$ or 12.7 and $38 \mathrm{~mm}$, respectively. The midspan deflection of the tensile 
surface of bend bars with respect to the points on the tensile surface aligned with the inner loading points was continuously monitored by a high-temperature three-probe extensometer (Applied Test System, Inc., Saxonburg, PA). The stress was directly applied through a sintered $\alpha$-SiC pushrod using a dead weight loading system. The test specimens were held at test temperatures for at least $30 \mathrm{~min}$. under a stress of $\sim 30-35 \mathrm{MPa}$ to allow the apparatus to reach an equilibrium condition before raising the stress to the desired level. The stress dependence of the creep rate was obtained by applying a single stress or by sequentially varying the applied stress for a fixed period of time $(\sim 100-150 \mathrm{~h})$. An average of at least three separate creep tests under a single or sequential stress condition was obtained at each temperature and applied stress condition. The creep rate versus time relationship was calculated from the displacement-time data curve to ensure that a steady state creep rate (or minimum creep rate) had been achieved. The applied stress and resultant creep strain were calculated from the load and displacement data using the procedures described by Hollenberg et al. 20 This procedure is based on the assumptions of (1) the material creep behavior is the same in both tension and compression, (2) the neutral axis lies along the center of the bend bars, and (3) steady creep rate is not sensitive to the strain applied. Note that recent creep studies 21,22 on the effect of stress states on the creep response of alumina and alumina composites indicated that both the creep rates and stress exponents of alumina and alumina composites were comparable whether loaded in tension, flexure, or compression. Thus, any errors in calculated flexural creep rate and stress responses as determined in the present study should be minimal.

Following creep testing the specimens were examined using optical and scanning electron microscopy to characterize the creep mechanisms and the accumulated creep damage in terms of microstructural and compositional parameters, applied stresses, and test temperatures. Transmission electron microscopy (TEM) was also employed to characterize the evolution of creep damage (i.e., creep cavitation and micro crack formation processes).

\section{RESULTS}

\section{Effects of Compositional Parameters}

Effect of Whisker Reinforcement. The creep results for polycrystalline alumina and alumina composites reinforced with $20 \mathrm{vol} \% \mathrm{SiC}$ whiskers at temperatures of $1200^{\circ}$ and $1300^{\circ} \mathrm{C}$, and at stress levels ranging from 35 to $300 \mathrm{MPa}$ in air, are summarized in Fig. 1. Note that the grain sizes of the alumina and composite are quite comparable ( 1.5 versus $2 \mu \mathrm{m}$ ). The data indicate that the alumina composite reinforced with 20 vol\% $\mathrm{SiC}$ whiskers is more creep resistant than unreinforced polycrystalline fine-grained alumina. For instance, the alumina composite exhibits creep rates that are approximately two orders of magnitude lower than the alumina under the same test conditions. Linear regression analysis of the creep rate versus stress curves for both alumina and alumina composite yields a stress exponent of $\sim 2$ in the relation of $\dot{\varepsilon} \propto \sigma^{n}$, indicative of a similar creep controlling mechanism. For fine-grained alumina, a stress exponent of 2 is attributed to grain boundary sliding (GBS).23,24 SEM observations on the tensile surface regions of crept alumina specimens revealed that alumina grains were sliding out of the tensile surface and rotating as a result of the GBS process. 16 TEM examinations revealed the formation of cavities at triple-grain junctions as a result of GBS that was not fully accommodated by diffusional processes.

Since the alumina composite exhibits a comparable stress exponent, one can conclude that it deforms by similar mechanisms. SEM observations of crept samples provide evidence of GBS processes. However, SiC whiskers that lie on grain boundaries and/or penetrate across the boundary planes inhibit the ability of grain boundaries to slide, resulting in an improvement in creep resistance accompanied by a decreased creep strain.

Effect of Whisker Content. The fracture resistance of alumina composites increased with whisker contents up to 30 vol\%. ${ }^{2}$ One might expect that a similar relationship applies to the creep response of alumina composite. Figure 2 shows the creep rate versus stress curves for alumina composites reinforced with 20,30 , and 50 vol\% $\mathrm{SiC}$ 


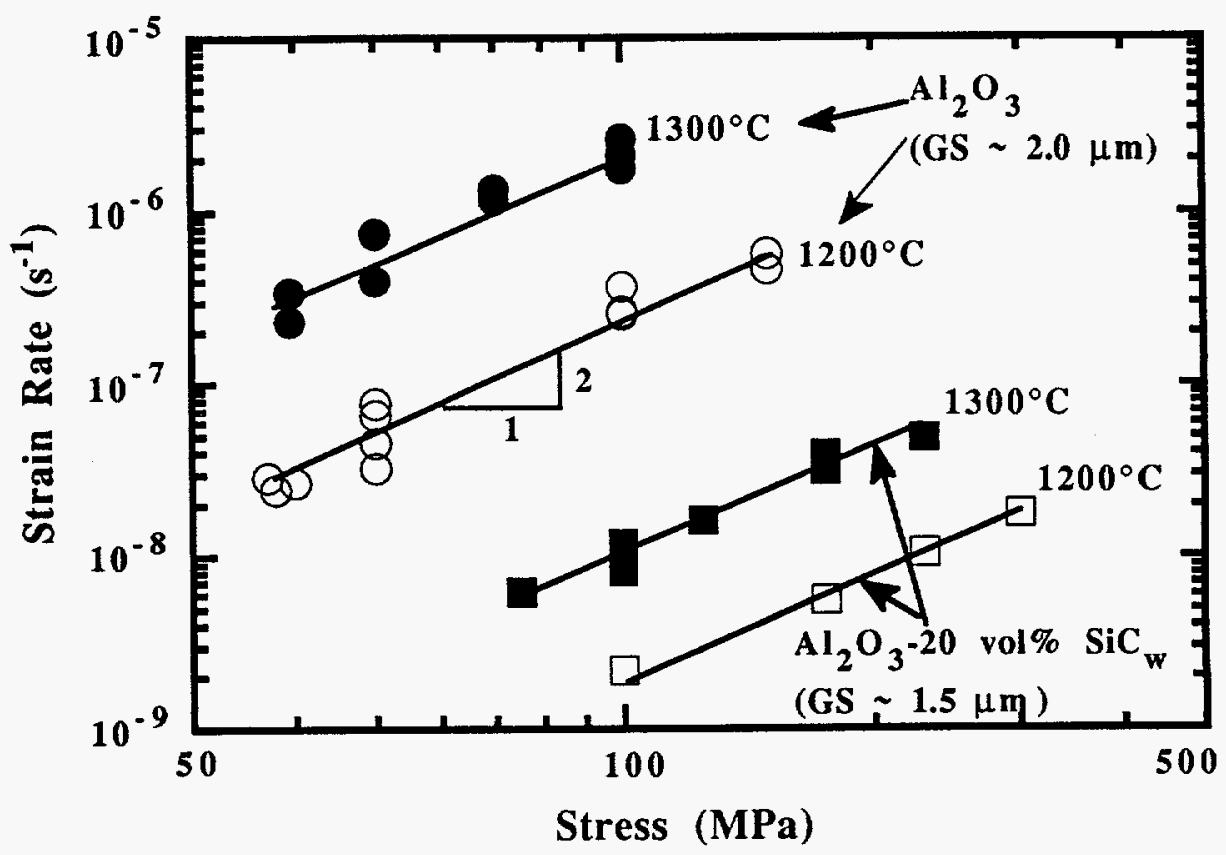

Figure 1. Strain rate versus stress results for polycrystalline fine-grained alumina and alumina- 20 vol\% $\mathrm{SiC}$ whisker composite tested at $1200^{\circ}$ and $1300^{\circ} \mathrm{C}$ in air.

whiskers at $1200^{\circ}$ and $1300^{\circ} \mathrm{C}$ under selected stress levels in air. The grain sizes in composites with whisker content $\geq 20 \mathrm{vol} \%$ are quite similar $(1-2 \mu \mathrm{m})$; thus grain size effects are negligible. Alumina composites reinforced with 30 and 50 vol\% whiskers exhibit higher creep rates, by 1-2 orders of magnitude, than the composite reinforced with only 20 vol\% whiskers. The 30 vol\% and 50 vol\% whisker composites also exhibit essentially the same creep rates at $1200^{\circ}$ and $1300^{\circ} \mathrm{C}$. In addition, the creep stress exponents of the 30 and 50 vol\% alumina composites at $1200^{\circ}$ and $1300^{\circ} \mathrm{C}$ are $\sim 3$ and 6 , respectively, which are greater than those obtained for the 20 vol\% alumina composite. The higher creep rates and stress exponents at these test temperatures for whisker content $\geq$ 30 vol\% suggest that additional processes are contributing to the creep deformation. In the

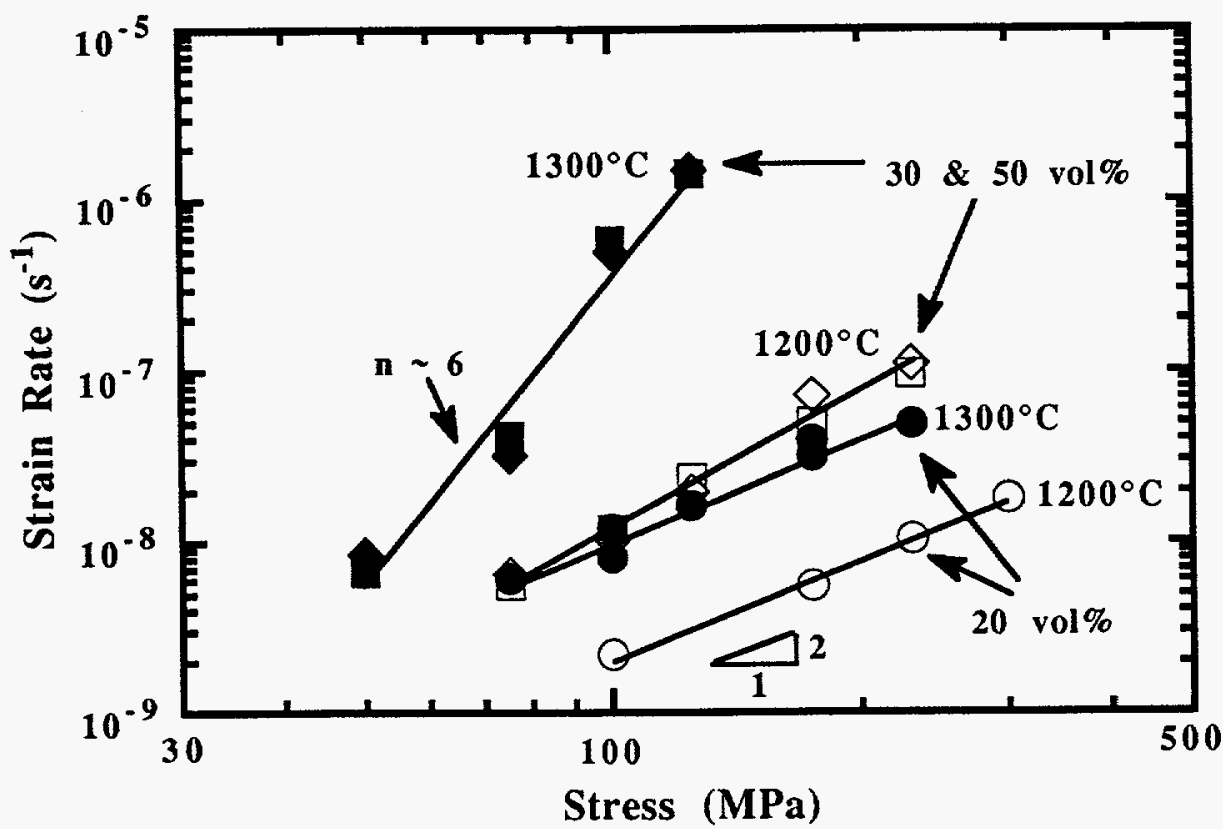

Figure 2. Strain rate versus stress curves for alumina composites reinforced with 20,30 and 50 vol\% SiC whiskers. The creep rates are much greater at whisker contents $\geq 30$ vol\% due to the extensive oxidation reaction and enhanced cavitation processes. 
case of structural ceramics, high creep rates plus high stress exponents are often associated with enhanced creep cavitation. 25,26

The TEM examinations of the tensile surface regions showed that the composites with whisker contents of 30 or $50 \mathrm{vol} \%$ exhibited higher number densities of cavities $(\sim 2$ 3 times) than those in the $20 \mathrm{vol} \%$ alumina composites. The whiskers may act as additional sites for stress concentration and, thus, cavity nucleation, resulting in higher cavity density with increased whisker content. In addition, both the alumina grains and whiskers in the tensile surface regions were often surrounded by an amorphous phase that was identified as a $\mathrm{CaO}$-containing aluminosilicate glass. 17 Such an extensive formation of amorphous phase was rarely observed in the 20 vol\% composite. The formation of silicate glass resulted from the oxidation of SiC whiskers. At higher whisker contents, not only more $\mathrm{SiO}_{2}$ can form, but the $\mathrm{SiC}$ whiskers are increasingly connected leading to rapid oxidation paths. This is further promoted by the extensive formation of cavitation and micro cracking at whisker contents $\geq 30 \mathrm{vol} \%$. Oxidation experiments at $1300^{\circ} \mathrm{C}$ indicated that the 30 and 50 vol\% composites exhibited a reaction constant that was three-time higher than that of $20 \mathrm{vol} \%$ composite. 17 The combination of a greater tendency of cavitation and micro cracking and more rapid oxidation enhances cavitation and thus creep rates.

Effect of Densification Additives. Additives are often employed to promote densification rate via formation of a liquid phase at the sintering temperature; in alumina composites reinforced with $\mathrm{SiC}$ whiskers, $\mathrm{Y}_{2} \mathrm{O}_{3}$ additions have been used. ${ }^{27} \mathrm{Here}, \mathrm{MgO}$ was also added to inhibit the alumina grain growth. 28 Figure 3 shows the effect of the addition of densification additives on the creep rates of alumina composites reinforced with $20 \mathrm{vol} \% \mathrm{SiC}$ whiskers at temperatures of $1200^{\circ}$ and $1300^{\circ} \mathrm{C}$. The composite with oxide additives exhibited creep rates that were one to three orders of magnitude higher than the composites which did not use the additives. Thus, the creep resistance of alumina-SiC composites was degraded by the addition of $\mathrm{Y}_{2} \mathrm{O}_{3}$ plus $\mathrm{MgO}$. In addition, the additivecontaining composite exhibited a stress exponent $(\sim 2.5)$ similar to the one without additives at $1200^{\circ} \mathrm{C}$, but had a higher exponent at $1300^{\circ} \mathrm{C}(\mathrm{n} \sim 4)$. The higher stress exponent obtained at $1300^{\circ} \mathrm{C}$ for composite with additives was found to be associated with the increased creep cavitation and oxidation.

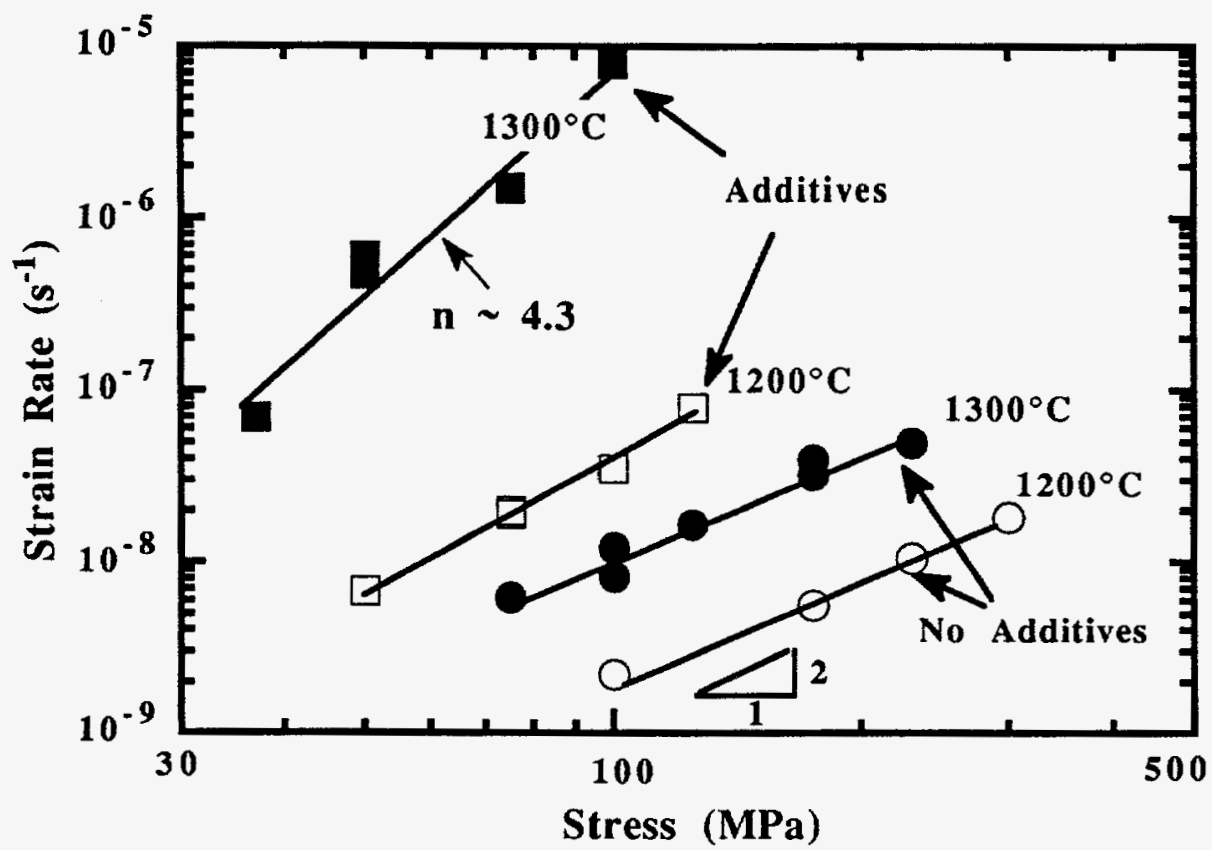

Figure 3. The creep resistance of alumina- $20 \mathrm{vol} \% \mathrm{SiC}$ composite is degraded by the use of $\mathrm{Y}_{2} \mathrm{O}_{3}$ (plus $\mathrm{MgO}$ ) additives due to the formation of amorphous intergranular phases.

TEM observations of the as-fabricated 20 vol\% SiC-alumina composite with $\mathrm{Y}_{2} \mathrm{O}_{3}$ (plus $\mathrm{MgO}$ ) additives also revealed the presence of an amorphous phase containing $\mathrm{Al}, \mathrm{Y}$, 
$\mathrm{Si}$, and $\mathrm{Ca}$ at triple grain junctions and grain boundaries. 17 In addition, extensive creep cavitation was also observed in the tensile surface region of the crept additive-containing material, similar to that observed in the alumina composites reinforced with $\geq 30 \mathrm{vol} \% \mathrm{SiC}$ whiskers. A substantial amount of surface oxidation scale associated with the formation of gas bubbles was also observed on the high-temperature fracture surface in the tensile surface region. The presence of a glassy phase at the grain boundaries facilitates GBS and cavitation, resulting in higher creep rates and stress exponents.

\section{Effects of Microstructural Parameters}

Effect of Matrix Grain Size. An increase in alumina matrix grain size leads to an increase in fracture resistance of alumina ceramics and composites reinforced with $\mathrm{SiC}$ whiskers 29 as well as the creep resistance of polycrystalline alumina. 30 A study was therefore undertaken to evaluate the effect of alumina grain size on the creep behavior of 10 vol\% SiC whisker-reinforced alumina composites. ${ }^{18}$ The composites exhibit grain sizes from 1.2 to $8 \mu \mathrm{m}$ achieved by the use of controlled hot-pressing conditions. Figure 4 summarizes the creep results of alumina- $10 \mathrm{vol} \% \mathrm{SiC}$ composites at $1200^{\circ} \mathrm{C}$ under applied stresses of 100 to $230 \mathrm{MPa}$ in air. The results showed that the creep rate decreased with increasing matrix grain size. For instance, the composite with a $8-\mu \mathrm{m}$ matrix grain size exhibited a creep rate that was $\sim 10$ times lower than the composite with a $1.2-\mu \mathrm{m}$ matrix grain size. The grain size exponent in this case can be obtained from the slop of the log creep rate versus log alumina grain size curves at a constant applied stress. The results revealed that the grain size exponent was $\sim$ minus one for all stress levels up to $230 \mathrm{MPa}$. In addition, the regression analysis of the log creep rate versus log stress curves yielded a stress exponent of $\sim$ two. The stress exponent was insensitive to the matrix grain size range investigated in this study. Again, a stress exponent of two can be associated with grain boundary sliding. Early studies also indicated that the creep rate due to the GBS process should be proportional to the $\mathrm{d}^{-1}$ ( $\mathrm{d}$ is the matrix grain size)..$^{31-34}$

SEM examinations of the tensile surface regions of materials having 1.2 and 8.0 $\mu \mathrm{m}$ grain size indicated that the $1.2-\mu \mathrm{m}$ materials had more prominent examples of alumina grains sliding out of the tensile surface and grain rotation as compared with the features

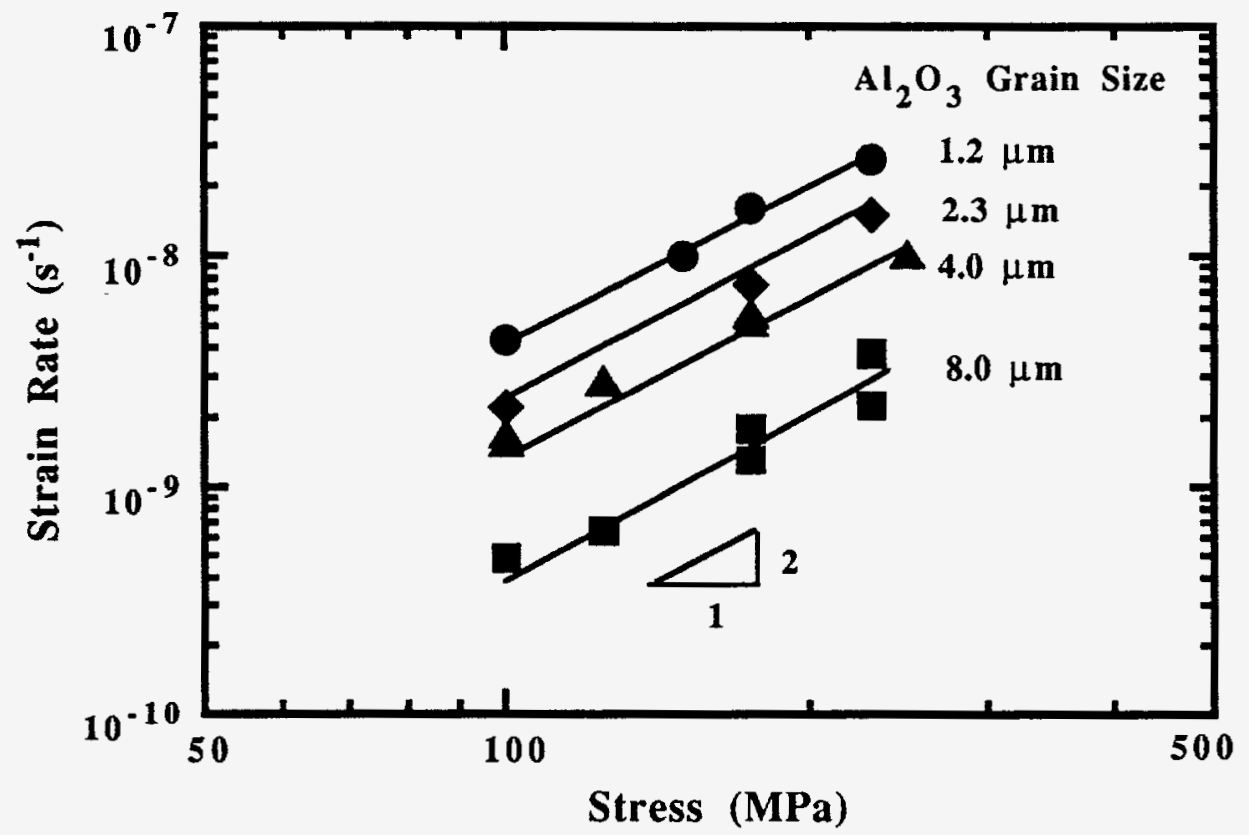

Figure 4. Creep rate versus stress curves at $1200^{\circ} \mathrm{C}$ for alumina-10 vol\% $\mathrm{SiC}$ composites as a function of alumina matrix grain size. The creep resistance of alumina composites is improved by an increase in matrix alumina grain size. 
observed for the $8.0-\mu \mathrm{m}$ material. ${ }^{18}$ Thus, the contribution from the GBS process to the creep deformation rate (and creep strain) decreases with increasing the matrix grain size, resulting in an increase in creep resistance under the employed test conditions at which only limited creep damage accumulation occurs.

Effect of Whisker Aspect Ratio. As shown earlier, the increased creep resistance of polycrystalline alumina containing $20 \mathrm{vol} \% \mathrm{SiC}$ whiskers is attributed to the mechanical grain-boundary pinning/bridging by the nondeforming SiC whiskers, which inhibit the grain boundary sliding. $13,16,17$ However, another suggestion is that the increased creep resistance of these alumina composites is due to the formation of a rigid network of interconnected whiskers, which are not free to rotate or slide with respect to each other. 14,35,36 As a result, increases in whisker aspect ratio or whisker content may lead to a greater tendency to form a whisker network and thus increase the creep resistance of alumina composites. Note that the whiskers used in the Ref. [14] were not obtained from the same source and processed by the same method, which may introduce differences in impurities and whisker strengths. Therefore, a study was undertaken to provide insight into the effect of the whisker aspect ratio on the creep rate of alumina composites reinforced with 10 vol\% SiC whiskers. The alumina powder-SiC whisker mixture was obtained from a single commercial source (same $\mathrm{SiC}$ whiskers as previous studies reported here). The as-received mixtures and mixtures that were ball-milled were hot-pressed at $1650^{\circ} \mathrm{C} / 2 \mathrm{~h}$ and $1850^{\circ} \mathrm{C} / 2 \mathrm{~h}$, respectively. Note that the alumina matrix grain sizes in these two materials were quite similar $(\sim 1-2 \mu \mathrm{m})$; the hot-pressing temperatures were altered to obtain similar matrix grain sizes.

Figure 5 shows the creep results at $1200^{\circ}$ and $1300^{\circ} \mathrm{C}$ for alumina- 10 vol\% SiC whisker composites made from mixtures in the as-received and after $100 \mathrm{~h}$ ball-mill conditions. The results indicate that the creep resistance of 10 vol\% SiC-alumina composite is improved by decreasing the aspect ratio of $\mathrm{SiC}$ whiskers. For instance, the composite from the ball-milled mixtures exhibited creep rates that were 4 - 7 times lower than those for the material fabricated from the as-received mixtures under the same test conditions. In addition, the composite from the ball-milled mixtures exhibited a stress exponent of $\sim 2$ at both $1200^{\circ}$ and $1300^{\circ} \mathrm{C}$, whereas the composite from the as-received mixture showed a transition to a higher stress exponent $(n \sim 5)$ and a further increase in creep rate at $1300^{\circ} \mathrm{C}$. This transition to the higher stress exponent plus higher creep rate was associated with the occurrence of extensive creep cavitation at $1300^{\circ} \mathrm{C}$.

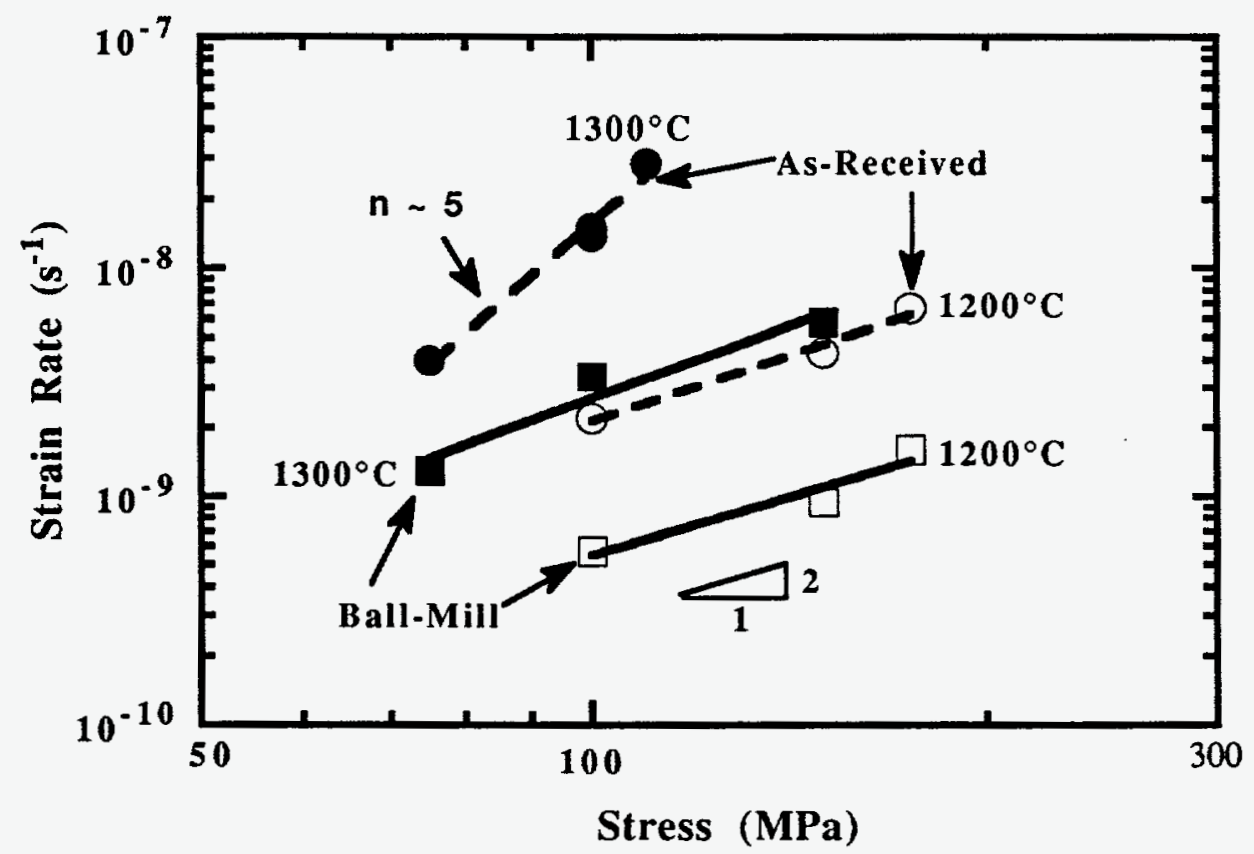

Figure 5. Strain rate versus applied stress curves for 10 vol\% SiC-alumina composites containing asreceived or $100 \mathrm{~h}$-ball-mill mixtures. The creep rate is decreased by decreasing the whisker aspect ratio (increasing the number density of whisker per unit grain-boundary surface area). 
Note that the strain to failure for composite from the as-received mixtures was generally 3 to 5 times greater than those obtained in the composite with the ball-milled mixtures.

The SEM observations of the hot-pressed specimens showed that the whisker aspect ratio in the composite from the as-received mixtures ranged from 3-30, whereas the ratio in the composite with the ball-milled mixtures was from 1- 10. In addition, the number density of whiskers with aspect ratio of $\sim 1-2$ in the composite from the ball-mill mixtures was at least 5 times higher than those in the composite with the as-received mixtures. 19 Examinations on the tensile surface regions of materials with as-received mixtures revealed a greater extent of grain offset and grain rotation as compared to that observed in the composite containing the ball-mill mixtures. The reduction in whisker aspect ratio thus leads to an increase in number density of hard whiskers and/or particles per unit surface area of grain boundary (i.e., constant grain size) to inhibit the creep deformation by GBS process. This pinning effect was also evident by the observed greater effectiveness of $\mathrm{SiC}$ whisker and/or particle in inhibiting matrix grain growth .

\section{DISCUSSION}

\section{Effects of Compositional Parameters}

It has been shown that the creep deformation in both fine-grain alumina and $\mathrm{SiC}$ whisker-reinforced composites was governed by a GBS process and by nucleation, growth, and coalescence of grain boundary cavities, as confirmed by electron microscopy studies. 16,17 Such processes ultimately lead to crack formation and growth, and finally to catastrophic failure of the materials. The presence of SiC whiskers, which pin and bridge grain boundaries, substantially retards the GBS deformation process, enhancing the creep resistance of alumina composite. However, the presence of $\mathrm{SiC}$ whiskers also promotes the number density of creep cavities and reduces the strain to failure.

The excellent creep resistance seen in the alumina composite reinforced with 20 vol\% $\mathrm{SiC}$ was degraded at whisker contents $\geq 30$ vol\%. The degradation in creep properties arose from the promotion of extensive creep cavitation, due to a substantial increase in the cavity nucleation sites such as whiskers and whisker/matrix interfaces, as compared with those in the $20 \mathrm{vol} \%$ composite. This was associated with an enhanced oxidation reaction of $\mathrm{SiC}$ whiskers at contents $\geq 30 \mathrm{vol} \%$ as confirmed by oxidation experiments. An increase in whisker contents develops more interconnected paths for oxidation and more $\mathrm{SiC}$ whiskers to oxidize. Oxidation of $\mathrm{SiC}$ whiskers leads to the formation of glassy phases at grain boundaries, whisker/matrix interfaces at the surface, and along any surface cracks. In addition, the presence of impurities from whiskers (i.e., $\mathrm{Ca}$ and $\mathrm{Fe})^{37}$ will further reduce the viscosity of the glass phase formed. The combination of extensive oxidation (and thus formation of glassy phases) and reduction in viscosity will accelerate the creep deformation in the tensile subsurface regions by elevating GBS. During creep, the internal oxidation is much more limited without crack formation via cavity growth and coalescence. However, the generation of surface cracks will act as fast diffusion paths for oxygen transport, thus resulting in greater internal oxidation reaction. The internal glassy phases at grain boundaries can enhance the GBS process, thus increasing creep cavitation and creep rate. Therefore, the higher creep rates and stress exponents of alumina composites with 30 and $50 \mathrm{vol} \%$ whiskers are attributed to the greater oxidation rates and the resultant promotion of creep cavities by the formation of intergranular glassy phases.

The creep results of alumina-SiC composites sintered with additives versus those without additives indicate that the excellent creep resistance of alumina composites can be diminished due to the introduction of an intergranular glassy phase. In the present study, the glassy phases were introduced by the addition of $\mathrm{Y}_{2} \mathrm{O}_{3}$ plus $\mathrm{MgO}$ densification additives. The presence of glassy phases at grain boundaries promotes GBS, leading to higher creep rates. ${ }^{38}$ In addition, the intergranular glassy phases will act as fast diffusion paths at elevated temperatures, thus promoting creep and oxidation processes. As a result, these can be a substantial increase in the number density of creep cavities in the tensile surface regions, when compared with the materials prepared without oxide additives. In addition, the presence of impurities such as $\mathrm{Ca}$ and $\mathrm{Fe}$ from whiskers will reduce the glass 
viscosity, enhancing the creep deformation rates and creep cavitation. These observations are similar to those in the alumina composites containing whisker $\geq 30$ vol\% as a result of the rapid and extensive oxidation and glass formation. As temperature increases, a further reduction in the viscosity of glass will promote GBS process and cavitation, as seen in the case for the additive-containing composite tested at $1300^{\circ} \mathrm{C}$.

The presence of glassy phase(s) at grain boundary has been known to enhance creep processes in both monolithic and composites at elevated temperatures in air. Consequently, higher creep rates and stress exponents have been reported for vitreousbonded alumina, silicon nitrides, and $\mathrm{Si}_{3} \mathrm{~N}_{4}$-based composites. ${ }^{38-41}$ Nonetheless, the creep resistance of glass-containing ceramics can be improved by a post fabrication heattreatment to crystallize the glassy phase(s). ${ }^{42}$ The crystallization decreases the volume content of the glass and reduces the contribution from viscous flow of the glassy phase, suppressing creep cavitation.

\section{Effect of Microstructural Parameters}

As shown, the creep resistance of alumina-SiC composites was improved by increasing the alumina matrix grain size at a constant whisker content (Fig. 5). An increase in alumina matrix grain size reduces the contribution from GBS processes to the creep rates $\left(\dot{\varepsilon} \propto d^{-1}\right.$ ) and the creep strain, as evident by the SEM observations. In addition, an increase in grain size will also decrease the total grain-boundary surface area and thus could increase the number density of whiskers per unit grain-boundary area, enhancing the pinning/bridging effect of the nondeforming whiskers. It should be noted that this positive dependence of creep resistance on grain size is only valid under conditions at which only limited creep damage (cavitation and crack formation) occurs. It was observed that the conditions (higher temperatures and/or stresses), which promotes cavity generation and surface crack formation, could offset the grain size contribution to the creep resistance. ${ }^{18}$

The creep resistance of alumina-SiC composites was also enhanced by decreasing the aspect ratio of whiskers, for constant alumina matrix grain size and whisker content, using the same whisker source. Earlier studies had suggested that creep rates decrease with increase in the whisker aspect ratio using a different whisker source. ${ }^{14}$ A decrease in whisker aspect ratio increases the number density of $\mathrm{SiC}$ particles/whiskers per unit grainboundary area. The increase in the number of whiskers per grain boundary should enhance the pinning and bridging effects of the whiskers and inhibit the GBS process. This is consistent with our observations of decreases in the creep rates and strains with decreased whisker aspect ratio.

\section{SUMMARY}

The present studies were undertaken to investigate the effects of microstructural and compositional parameters on the flexural creep behavior of alumina composites reinforced with $\mathrm{SiC}$ whiskers at 1200 and $1300^{\circ} \mathrm{C}$ in air. This has helped to establish guidelines for improving the high-temperature creep properties of alumina-SiC composites.

The results showed that the incorporation of 20 vol\% SiC whisker can substantially improve the creep resistance of polycrystalline fine-grained alumina under the test condition employed. The enhancement in creep resistance is attributed to the presence of SiC whiskers that inhibit the creep deformation by GBS process. At the same time, the alumina composite containing 20 vol\% SiC whiskers exhibited creep rates that were $1-2$ orders of magnitude lower than those with 30 and 50 vol\% SiC whiskers. The degradation in creep resistance with whisker contents $\geq 30 \mathrm{vol} \%$ is due to a combination of extensive creep cavitation and enhanced oxidation reaction of $\mathrm{SiC}$ whiskers. In addition, the creep resistance of alumina-20 vol\% $\mathrm{SiC}$ composite was degraded by the formation of a substantial amount of intergranular glassy phase when $\mathrm{Y}_{2} \mathrm{O}_{3}$ plus $\mathrm{MgO}$ densification additives were present. The presence of glassy phase at grain boundaries and whisker/matrix interfaces facilitated GBS and cavity formation, therefore enhancing the creep rates.

The creep resistance of $10 \mathrm{vol} \% \mathrm{SiC}$-alumina composites at $1200^{\circ} \mathrm{C}$ increased with matrix grain size. This behavior was a result of a reduced GBS contribution to the creep 
strains and creep rates. The creep resistance of alumina composites was also improved by reducing the whisker aspect ratio at constant whisker content. A reduction in whisker aspect ratio increases the number density of whiskers/particles present per grain boundary, enhancing the grain boundary pinning effects and thus creep resistance.

\section{ACKNOWLEDGMENT}

The authors acknowledge the important experimental contributions of S. B. Waters and W. H. Warwick and thank Drs. K. P. Plucknett and S.-L. Hwang for reviewing the manuscript. Research sponsored by the U.S. Department of Energy, Assistant Secretary for Energy Efficiency and Renewable Energy, Office of Transportation Technologies, as part of the Ceramic Technology Project of the Materials Development Program, under contract DE-AC05-84OR21400 with Martin Marietta Energy Systems, Inc.

\section{REFERENCES}

1. T. N. Tiegs and P. F. Becher, "Thermal shock behavior of an alumina-SiC whisker composite," J. Am. Ceram. Soc., 70 [5], C-109-C-111 (1987).

2. P. F. Becher, T. N. Tiegs, J. C. Ogle and W. H. Warwick, "Toughening of ceramics by whisker reinforcement," pp. 61-73, in: "Fracture Mechanics of Ceramics, Vol. 7," R. C. Bradt, A. G. Evans, D.P.H. Hasselman and F. F. Lange, eds., Plenum Publ. Corp., New York, (1986).

3. P. F. Becher, P. Angelini, W. H. Warwick, and T. N. Tiegs, "Elevated-temperaturedelayed failure of alumina reinforced with 20 vol\% silicon carbide whiskers," J. Am. Ceram. Soc., 73 [1], 91-96 (1990).

4. L. X. Han and S. Suresh, "High-temperature failure of an alumina-silicon carbide composite under cyclic loads: mechanisms of fatigue crack-tip damage," J. Am. Ceram. Soc., 72 [7] 1233-38 (1989).

5. R. H. Dauskardt, B. J. Dalgleish, D. Yao, R. O. Ritchie, and P. F. Becher, "Cyclic fatigue-crack propagation in a silicon carbide whisker-reinforced alumina composite: role of load ratio," J. Mater. Sci. 28 (1993) 3258-3266.

6. P. F. Becher, C. H. Hsueh, P. Angelini, and T. N. Tiegs, "Toughening behavior in whisker-reinforced ceramic matrix composites," J. Am. Ceram. Soc., 71 [12] 1050-61 (1988).

7. A. H. Chokshi and J. R. Porter, "Creep deformation of an alumina matrix composite reinforced with silicon carbide whiskers," J. Am. Ceram. Soc., 68 [6], C-144C-145 (1987).

8. P. F. Becher and T. N. Tiegs, "Temperature dependence of strengthening by whisker reinforcement: SiC whisker-reinforced alumina in air," Advanced Ceramic Materials, Vol. 3, No. 2, pp. 148-153 (1988).

9. L. X. Han, R. Warren, and S. Suresh, "An experimental study of toughening and degradation due to microcracking in a ceramic composite," Acta Metall. Mater. Vol. 40, No.2, pp. 259-274 (1992).

10. G. D. Quinn, "Fracture mechanism maps for advanced structural ceramics: part 1 methodology and hot-pressed silicon nitride results," J. Mater. Sci. 25 (1990) 4361-4376.

11. G. D. Quinn, "Fracture mechanism maps for advanced structural ceramics: part 2 sintered silicon nitride results," J. Mater. Sci. 25 (1990) 4377-4392.

12. J. R. Porter and A. H. Chokshi, "Creep performance of silicon carbide whiskerreinforced alumina," pg. 919-28, in: "Ceramic Microstructures '86: The Role of Interfaces," J. A. Pask and A. G. Evans, eds., Plenum Press, New York, (1987).

13. A. R. de Arellano-López, F. L. Cumbrera, A. Domínguez-Rodríguez, K. C. Goretta, and J. L. Routbort, "Compressive creep of SiC-whisker-reinforced $\mathrm{Al}_{2} \mathrm{O}_{3}, " J$. Am. Ceram. Soc., 73 [5], 1297-300 (1990). 
14. J. R. Porter and J. J. Ratto, "Microstructural aspects of creep in SiC whiskerreinforced $\mathrm{Al}_{2} \mathrm{O}_{3}$," pp. 381-89, in: "Proceedings of Metals \& Ceramics Matrix Composites: Processing, Modeling \& Mechanical Behavior," R. B. Bhagat, A. H. Clauer, P. Kumar and A. M. Ritter, eds., the Minerals, Metals \& Materials Society, (1990).

15. P. Lipetzky, S. R. Nutt, D. A. Koester, and R. F. Davis, "Atmospheric effects on compressive creep of SiC-whisker-reinforced alumina," J. Am Ceram. Soc., 74 [6] 1240-47 (1991).

16. H. T. Lin and P. F. Becher, "Creep behavior of a $\mathrm{SiC}$ whisker reinforced alumina," $J$. Am. Ceram. Soc., 73 [5], 1378-1381 (1990).

17. H. T. Lin and P. F. Becher, "High-temperature creep deformation of alumina-SiCwhisker composites," J. Am. Ceram. Soc., 74 [8] 1886-93 (1991).

18. H. T. Lin and P. F. Becher, "Grain size effect on creep deformation of alumina-SiC composites," submitted to J. Am. Ceram. Soc.

19. H. T. Lin and P. F. Becher, "Effect of whisker aspect ratio on creep of alumina-SiC composites," to be published.

20. G. W. Hollenberg, G. R. Terwilliger, and R. S. Gordon, "Calculation of stress and strain in four-point bending creep test," J. Am. Ceram. Soc., 54 [4], 196-199 (1971).

21. A. G. Robertson, D. S. Wilkinson, and C. H. Cáceres, "Creep and creep fracture in hot-pressed alumina," J. Am. Ceram. Soc., 74 [5] 915-21 (19991).

22. H. T. Lin and P. F. Becher, "Effect of applied stress state on creep response of alumina-SiC-whisker composite," to be published.

23. A. H. Heuer, N. J. Tighe, and R. M. Cannon, "Plastic deformation of fine-grained alumina $\left(\mathrm{Al}_{2} \mathrm{O}_{3}\right)$ : II. basal slip and nonaccommodated grain-boundary sliding," $J$. Am. Ceram. Soc., 63 [1-2] 53-58 (1980).

24. T. Sugita and J. A. Pask, "Creep of doped polycrystalline $\mathrm{Al}_{2} \mathrm{O}_{3}$, " J. Am. Ceram. Soc., 53 [11] 609-13 (1970).

25. S. M. Wiederhorn, D. E. Roberts, T.-J. Chung, and L. Chuck, "Damage-enhanced creep in a siliconized silicon carbide," J. Am. Ceram. Soc., 71 [7] 602-08 (1988).

26. D. F. Carroll and R. E. Tressler, "Effect of creep damage on the tensile creep behavior of a siliconized silicon carbide, "J. Am. Ceram. Soc., 72 [1] 49-53 (1990).

27. T. N. Tiegs and P. F. Becher, "Sintered $\mathrm{Al}_{2} \mathrm{O}_{3}-\mathrm{SiC}$-whisker composites," $\mathrm{Am}$. Ceram. Bull., 66 [2] 339-42 (1987).

28. A. H. Heuer, "The role of MgO in the sintering of alumina," J. Am. Ceram. Soc., 62 [5-6] 317-18 (1979).

29. P. F. Becher "Recent advances in whisker-reinforced ceramics," Annu. Rev. Mater. Sci. 20, 179-95 (1990).

30. A. H. Heuer, R. M. Cannon, and N. J. Tighe, "Plastic deformation in fine-grained ceramics," pp. 339-65, in: "Proceedings of the 15th Sagamore Army Materials Research Conference, Ultrafine-Grain Ceramics," J. J. Burke, N. L. Reed, and V. Weiss, eds., Syracuse University Press, New York, (1970).

31. T. G. Langdon, Grain boundary deformation process," pp. 101-126, in: "Deformation of Ceramic Materials II," R. E. Tressler and R. C. Bradt, eds., Plenum Press, New York, (1984).

32. N. K. Sinha, "Grain boundary sliding in polycrystalline materials," Phil. Mag. A, 40, 825-42 (1979).

33. T. G. Langdon, "Grain boundary sliding as a deformation mechanism during creep," Phil. Mag. A, 22, 689-700 (1970).

34. A. H. Chokshi, "An evaluation of the grain-boundary sliding contribution to creep deformation in polycrystalline alumina, "J. Mater. Sci., 25 (1990) 3221-3228.

35. J. R. Porter, "Dispersion processing of creep resistant whisker-reinforced ceramicmatrix composites," Mater. Sci. Eng., A107, 127-132 (1989).

36. J. R. Porter, "Observations of non-steady creep in SiC whisker reinforced alumina," p. 147, in: "Proc. Int. Conf. on whisker-and-fiber-toughened ceramics," P. F. Becher, R. A. Bradley, and D. R. Johnson, eds., ASM, Metals Park, (1988).

37. S. R. Nutt, "Microstructure and growth model for rice-hull-derived SiC whiskers," $J$. Am. Ceram. Soc., 71 [3] 149-156 (1988). 
38. R. L. Tsai and R. Raj, "Creep fracture in ceramics containing a small amount of liquid phase," Acta Metall., 30, 1043-58 (1982).

39. S. W. Wiederhorn, B. J. Hockey, R. F. Krause, Jr., and K. Jakus, "Creep and fracture of a vitreous-bonded alumina oxide," J. Mater. Sci, 21, (1986) 810-24.

40. M. H. Lewis, G. R. Heath, S. M. Winder, and R. J. Lumby, "High temperature creep and fracture of $\beta^{\prime}-\mathrm{Si}_{3} \mathrm{~N}_{4}$ ceramic alloys," pp. 605-16, in: "Materials Science Research, Vol.18, Deformation of Ceramic Materials II," R. E. Tressler and R. C. Bradt, eds., Plenum Press, New York, (1984).

41. R. D. Nixon, S. Chevacharoenkul, M. L. Huckbee, S. T. Buljan, and R. F. Davis, "Deformation behavior of SiC whisker reinforced Si3N4," pp. 295-302, in: MRS Symposium Proceedings, Vol. 78, Advanced Structural Ceramics," P. F. Becher, M. V. Swain, and S. Somiya, eds., Materials Research Society, Pittsburgh, PA, (1987).

42. M. H. Lewis, S. Mason, and A. Szweda, "Syalon ceramic for application at high temperature and stress," pp. 175-190, in: "Non-Oxide Technical and Engineering Ceramics," S. Hampshire, ed., Elsevier Applied Science, New York, (1986).

\section{DISCLAIMER}

This report was prepared as an account of work sponsored by an agency of the United States Government. Neither the United States Government nor any agency thereof, nor any of their employees, makes any warranty, express or implied, or assumes any legal liability or responsibility for the accuracy, completeness, or usefulness of any information, apparatus, product, or process disclosed, or represents that its use would not infringe privately owned rights. Reference herein to any specific commercial product, process, or service by trade name, trademark, manufacturer, or otherwise does not necessarily constitute or imply its endorsement, recommendation, or favoring by the United States Government or any agency thereof. The views and opinions of authors expressed herein do not necessarily state or reflect those of the United States Government or any agency thereof. 